\title{
Investigando o uso de resíduos do processamento da madeira de eucalipto para a produção de combustíveis sólidos compactados
}

\section{Investigating the use of wastes from the processing of eucalyptus wood for the compacted solid fuels production}

\author{
Alessandro de Paulo Silva ${ }^{1}$, Azarias Machado de Andrade ${ }^{1}$, \\ Ananias Francisco Dias Júnior ${ }^{2}$
}

\author{
${ }^{1}$ Departamento de Produtos Florestais, DPF/UFFRJ, CEP: 23897-000, Seropédica, RJ, Brasil. \\ e-mail: apsflorestal@yahoo.com.br, azarias@ufrrj.br \\ ${ }^{2}$ Departamento de Ciências Florestais e da Madeira, DCFM/UFES, CEP: 29550-000, Jerônimo Monteiro, ES, Brasil. \\ e-mail: ananias.dias@ufes.br
}

\begin{abstract}
RESUMO
Este trabalho teve por objetivo analisar os carvões da casca, maravalha e serragem de Eucalyptus pellita, assim como os briquetes produzidos desses materiais, carbonizados em duas temperaturas. Para isso, a casca, maravalha e serragem oriundas do processamento mecânico foram carbonizados sob temperaturas de $400{ }^{\circ} \mathrm{C}$ e $600{ }^{\circ} \mathrm{C}$. As propriedades físico-químicas dos carvões produzidos foram comparadas com as do lenho carbonizado nas mesmas temperaturas. Em seguida os resíduos carbonizados foram briquetados e analisados através da umidade de equilíbrio, massa específica aparente, taxa de degradação natural e forçada. A carbonização da casca da madeira de Eucalyptus pellita proporcionou aumentos significativos nos rendimentos gravimétricos em carvão. Houve uma relação positiva entre a temperatura de carbonização e a umidade de equilíbrio dos briquetes produzidos com os resíduos carbonizados. Os briquetes produzidos com o carvão da casca carbonizada a $400{ }^{\circ} \mathrm{C}$ apresentaram elevado ritmo de degradação térmica.
\end{abstract}

Palavras-chave: processamento mecânico da madeira, aproveitamento de resíduos, sustentabilidade energética, briquetagem e densificação da biomassa.

\begin{abstract}
This study aimed to analyze the charcoals of bark, shavings and sawdust of Eucalyptus pellita, and the briquettes produced from these materials, carbonized at two temperatures. The bark, shavings and sawdust generated by mechanical processing were charred at temperatures of $400{ }^{\circ} \mathrm{C}$ and $600{ }^{\circ} \mathrm{C}$. The physicochemical properties of the charcoals produced were compared with those of the carbonized wood at the same temperatures. Then the charred residues were briquetted and analyzed through equilibrium moisture, apparent specific mass, natural and forced degradation rate. Carbonization of the bark of Eucalyptus pellita wood increased the gravimetric yields in charcoal. There was a positive relationship between the carbonization temperature and the equilibrium moisture of the briquettes produced with the carbonized residues. The briquettes produced with charcoal from the carbonized bark at $400{ }^{\circ} \mathrm{C}$ presented a high rate of thermal degradation.
\end{abstract}

Keywords: mechanical processing of wood, use of waste, energy sustainability, briquetting and densification.

\section{INTRODUÇÃO}

A madeira, desde a antiguidade, é um material muito importante e que devido as suas diversas utilidades e escassez nas regiões tradicionalmente consumidoras, vem valorizando-se ao longo das últimas décadas. Em alguns setores, o "desperdício" da madeira pode chegar a 70\% da massa original, como é o caso da sua utilização para transformação em madeira serrada [1]. Tal desperdício refere-se, basicamente, à grande geração de resíduos (serragem, maravalhas e costaneiras), que poderiam ser utilizados para outros fins, como para produção de energia térmica a partir da combustão ou queima direta. 
Outra finalidade seria a utilização para a transformação em carvão vegetal, pela submissão dos resíduos de madeira à ação do calor por meio da pirólise, com o intuito de concentrar carbono e retirar o oxigênio [2, 3, 4]. Entretanto, durante a conversão da madeira em carvão vegetal é possível a ocorrência de uma série de fenômenos físicos e químicos que resultam em outros subprodutos: uma fração gasosa que pode ser condensada, permitindo a obtenção do chamado líquido pirolenhoso e outra parte que culmina em gases não condensáveis inflamáveis, a exemplo do $\mathrm{CO}, \mathrm{H}_{2}, \mathrm{CH}_{4}$ e $\mathrm{C}_{2} \mathrm{H}_{6}$. O líquido pirolenhoso é basicamente constituído por água e compostos químicos orgânicos como os ácidos acético e fórmico, o éter, os álcoois metílico e etílico, a acetona e o alcatrão [6, 7, 8].

A elevação da temperatura final de carbonização proporciona incrementos no teor de carbono e reduções no rendimento em carvão e do teor de matérias voláteis. O carvão vegetal que apresentar elevado teor de matérias voláteis pode ainda apresentar incrementos proporcionais no poder calorífico, desde que os compostos voláteis sejam ricos em hidrogênio $[8,9,10,11]$. Há referências que indicam que a inclusão da casca no material a ser carbonizado, proporciona um aumento significativo dos rendimentos gravimétrico em carvão e em carbono fixo, apesar de um pequeno aumento no teor de cinza no carvão vegetal [12, 13]. Desde então, foram poucos os estudos que abordaram o aproveitamento de diversos resíduos madeireiros visando a produção de carvão vegetal. Atualmente, o conceito de biorefinaria direciona para o aproveitamento integral da madeira, nativa ou oriunda de plantios comerciais. Todavia, para colocar essa ideia em prática seriam necessárias ações que resultasse em parcerias entre silvicultura e a tecnologia de produtos florestais, visando a obtenção de vários produtos.

Para a produção de carvão vegetal e dos demais subprodutos da carbonização da lenha, é possível utilizar os resíduos gerados no desdobro das madeiras de Eucalyptus spp, como a serragem, topos, maravalha, cascas, costaneiras e demais refugos. Como os carvões produzidos a partir desses materiais, normalmente, apresentam baixas granulometrias médias e massas específicas, é interessante e viável a briquetagem antes da utilização propriamente dita na forma in natura.

A vantagem da briquetagem de resíduos de biomassa tem sido recomendada ainda sob o ponto de vista ambiental e econômico, considerando a alta disponibilidade desses materiais. Além disso, espera-se que os materiais compactados apresentem homogeneidade das suas características e maior densidade energética [14, $15,16,17]$. Tais procedimentos visam a concentração de maior estoque de energia por unidade de volume do combustível, além de facilitarem o manuseio, transporte e armazenamento [14, 18, 19, 20].

As unidades de processamento de base florestal têm baixo rendimento e são as grandes geradoras de resíduos, principalmente as de transformação primária. Segundo o Vieira et al. [17], as indústrias madeireiras geram resíduos da ordem de $27.750 .000 \mathrm{t} \mathrm{ano}^{-1}$, na forma de costaneiras, refilos, aparas, cascas, serragem, cepilhos ou maravalhas, etc., representando 90,7\% do volume total de resíduos gerados no país (construção civil e urbano). Diante do exposto, é de supor que a carbonização de resíduos oriundos do processamento da madeira de Eucalyptus proporcione melhorias significativas nas suas propriedades para o uso energético, subsidiando a obtenção de diversos produtos. É possível que o processo de briquetagem dos resíduos carbonizados resulte em combustíveis compactados com características satisfatórias para os diversos usos visando geração de energia.

Tendo por base o contexto referenciado anteriormente, este estudo objetivou a produção e análise de carvão vegetal do lenho, da casca, da maravalha e da serragem da madeira de Eucalyptus pellita, analisando os briquetes derivados dos referidos materiais carbonizados.

\section{MATERIAL E MÉTODOS}

\subsection{Obtenção da matéria-prima lignocelulósica}

As árvores de Eucalyptus pellita utilizadas foram provenientes de um povoamento florestal experimental com quinze anos de idade situado na Universidade Federal Rural do Rio de Janeiro, no município de Seropédica, Rio de Janeiro. Foram coletadas cinco árvores, de cujos fustes foram retirados seis discos de madeira com, aproximadamente, três centímetros de espessura, nas seguintes alturas: a 0,3 m do nível do solo, 1,30 m (altura do peito) e a $25 \%, 50 \%, 75 \%$ e $100 \%$ da altura comercial. Na ocasião foi separado o lenho dos resíduos, sendo eles: casca, maravalha e serragem, obtidos através de processamentos mecânicos diversos, em equipamentos da serraria da referida Instituição. Em seguida, o material foi acondicionado em embalagens plásticas previamente identificadas e encaminhado para as etapas subsequentes. 


\subsection{Carbonização dos materiais lignocelulósicos}

As amostras do material lenhoso foram cavaqueadas e juntamente com amostras dos resíduos do processamento foram secas até condição anidra em uma estufa regulada a $105 \pm 3{ }^{\circ} \mathrm{C}$. O material a.s. (absolutamente seco), das respectivas amostras (lenho, casca, maravalha e serragem), foi carbonizado em um cadinho metálico, inserido no interior de um forno mufla, sob as temperaturas máximas de $400{ }^{\circ} \mathrm{C}$ e $600{ }^{\circ} \mathrm{C}$. A taxa de aquecimento utilizada foi de $2,0^{\circ} \mathrm{C} \mathrm{min}^{-1}$. As composições analisadas no decorrer da pesquisa foram:

- Lenho de Eucalyptus pellita, carbonizado a $400{ }^{\circ} \mathrm{C}$ e a $600{ }^{\circ} \mathrm{C}$.

- Casca de Eucalyptus pellita, carbonizada a $400{ }^{\circ} \mathrm{C}$ e a $600{ }^{\circ} \mathrm{C}$.

- Maravalha da madeira de Eucalyptus pellita, carbonizada a $400{ }^{\circ} \mathrm{C}$ e a $600{ }^{\circ} \mathrm{C}$.

- Serragem da madeira de Eucalyptus pellita, carbonizada a $400{ }^{\circ} \mathrm{C}$ e a $600{ }^{\circ} \mathrm{C}$.

Os gases liberados durante as carbonizações foram condensados, quantificados e armazenados (líquido pirolenhoso). Os gases não-condensáveis, com alguns constituintes inflamáveis na composição, foram queimados na saída do sistema de arrefecimento. De posse das massas de cada um dos produtos (carvão e líquido) foram obtidos os rendimentos gravimétricos em carvão (RCV), em líquido pirolenhoso (RLP) e, por diferença, em gases não-condensáveis (RGNC).

\subsection{Análise da composição imediata dos carvões}

Após as determinações das respectivas massas totais, amostras representativas dos carvões foram separadas, maceradas e peneiradas. Foram utilizadas amostras com a granulometria média inferior a 1,00 mm e superior a $0,25 \mathrm{~mm}$, secas em estufa a $105 \pm 3{ }^{\circ} \mathrm{C}$ por 48 horas. Posteriormente, as análises foram conduzidas utilizando-se alíquotas de 1 grama, adotando-se a norma ASTM D 1762-64 [21], determinando-se os teores de matérias voláteis (TMV), de cinza (TCZ) e de carbono fixo (TCF). De posse do rendimento gravimétrico em carvão e do teor de carbono obteve-se o rendimento em carbono fixo (RCF).

\subsection{Produção e avaliação dos combustíveis sólidos compactados}

A briquetagem foi efetuada no interior de um molde metálico cilíndrico, de aço inoxidável, utilizando-se uma prensa hidráulica com capacidade de $15 \mathrm{t}$. Como agente aglutinante foi utilizada a carboximetilcelulose, na concentração de 3\% (3g/l de água). Na fabricação de cada briquete foram utilizados 60 gramas da mistura (material carbonizado e aglutinante). As misturas das composições foram inseridas no molde e prensadas com aplicação da uma carga de 10 t. Adotou-se o tempo de prensagem de três minutos e, posteriormente, os briquetes foram retirados e secos ao ar, até atingirem a umidade de equilíbrio com o ambiente. Em seguida, determinaram-se as massas específicas aparentes dos briquetes, de acordo com o método hidrostático, descrito pela norma NBR 11941 [22].

Foram determinados os ritmos de degradação dos briquetes, sob duas condições. Na primeira, incidiu-se a chama de um maçarico $\left(180^{\circ} \mathrm{C}\right)$ sobre o briquete a uma distância de $5 \mathrm{~cm}$ por cinco minutos, sendo esta a degradação forçada. A segunda condição considerou a degradação térmica contínua e natural, durante o período de 120 minutos, iniciando a ignição com auxílio do mesmo maçarico, mesma temperatura $\left(180{ }^{\circ} \mathrm{C}\right)$ e distância $(5 \mathrm{~cm})$. Em ambas as condições os briquetes foram pesados antes e depois da queima nos períodos pré-estipulados, para a determinação dos ritmos de degradação térmica. Este ensaio foi conduzido com base no estudo de Dias Júnior et al. [23].

\subsection{Análise dos dados}

Os resultados foram analisados por meio de um delineamento inteiramente aleatorizado (DIA), tipo fatorial 4 x 2, sendo: quatro tratamentos (tipo do resíduo), duas temperaturas de carbonização $\left(400\right.$ e $\left.600{ }^{\circ} \mathrm{C}\right)$ e com cinco repetições. Assim, os dados obtidos foram submetidos ao teste de Kolmogorov-Smirnov para verificação da normalidade. Para verificar a homogeneidade das variâncias foi aplicado o teste de Levene, pois uma das hipóteses da análise de variância é que as variâncias sejam iguais para a categoria analisada. Verificadas essas suposições, foi realizada a análise de variância e quando necessário, foi aplicado o teste de Tukey para comparação múltipla das médias.

A análise de regressão, com base no teste $\mathrm{F}$, foi conduzida visando identificar a influência das temperaturas de carbonização sobre as variáveis analisadas. O teste $t$ foi aplicado para analisar individualmente os coeficientes $\mathrm{R}^{2}$ dentro das equações obtidas. Quando necessário, os modelos foram ajustados para melhorar os valores do erro padrão (EP) e do coeficiente de determinação. Todos os testes foram conduzidos ao nível de $95 \%$ de probabilidade. 


\section{RESULTADOS}

De acordo com a Tabela 1 e a Figura 1A, percebe-se que o aumento da temperatura provocou diminuição no rendimento em carvão vegetal.

Tabela 1: Rendimentos em carvão vegetal (RCV), líquido pirolenhoso (RLP) e em gases não-condensáveis (RGNC).

Table 1: Yields of charcoal (YC), pyroligneous liquid (PL) and non-condensable gases (NCG).

\begin{tabular}{ccc|cc|cc}
\multirow{2}{*}{ Material } & \multicolumn{2}{c}{ RCV $(\boldsymbol{\%})$} & \multicolumn{2}{c}{ RLP $(\boldsymbol{\%})$} & \multicolumn{2}{c}{ RGNC (\%) } \\
\cline { 2 - 7 } & $\mathbf{4 0 0}^{\circ} \mathbf{C}$ & $\mathbf{6 0 0}^{\circ} \mathbf{C}$ & $\mathbf{4 0 0}^{\circ} \mathbf{C}$ & $\mathbf{6 0 0}^{\circ} \mathbf{C}$ & $\mathbf{4 0 0}^{\circ} \mathbf{C}$ & $\mathbf{6 0 0}^{\circ} \mathbf{C}$ \\
\hline Lenho & $30,74^{\mathrm{bA}}$ & $27,37^{\mathrm{bB}}$ & $44,53^{\mathrm{aA}}$ & $42,83^{\mathrm{bA}}$ & $24,73^{\mathrm{bB}}$ & $29,80^{\mathrm{bA}}$ \\
Casca & $38,27^{\mathrm{aA}}$ & $33,49^{\mathrm{aB}}$ & $31,97^{\mathrm{cA}}$ & $31,87^{\mathrm{cA}}$ & $29,77^{\mathrm{aB}}$ & $34,63^{\mathrm{aA}}$ \\
Maravalha & $28,23^{\mathrm{bA}}$ & $24,78^{\mathrm{cB}}$ & $46,38^{\mathrm{aA}}$ & $47,59^{\mathrm{aA}}$ & $25,39^{\mathrm{bA}}$ & $27,63^{\mathrm{bA}}$ \\
Serragem & $29,38^{\mathrm{bA}}$ & $26,02^{\mathrm{bB}}$ & $39,63^{\mathrm{bA}}$ & $39,25^{\mathrm{bA}}$ & $30,98^{\mathrm{aB}}$ & $34,73^{\mathrm{aA}}$ \\
\hline
\end{tabular}

Letras minúsculas diferentes na mesma coluna indicam diferenças estatísticas entre as variáveis para cada tipo de resíduo do processamento da madeira de Eucalyptus pellita; letras maiúsculas diferentes na mesma linha indicam diferenças estatísticas entre as temperaturas de carbonização. Comparação múltipla pelo teste de Tukey a 95\% de probabilidade.

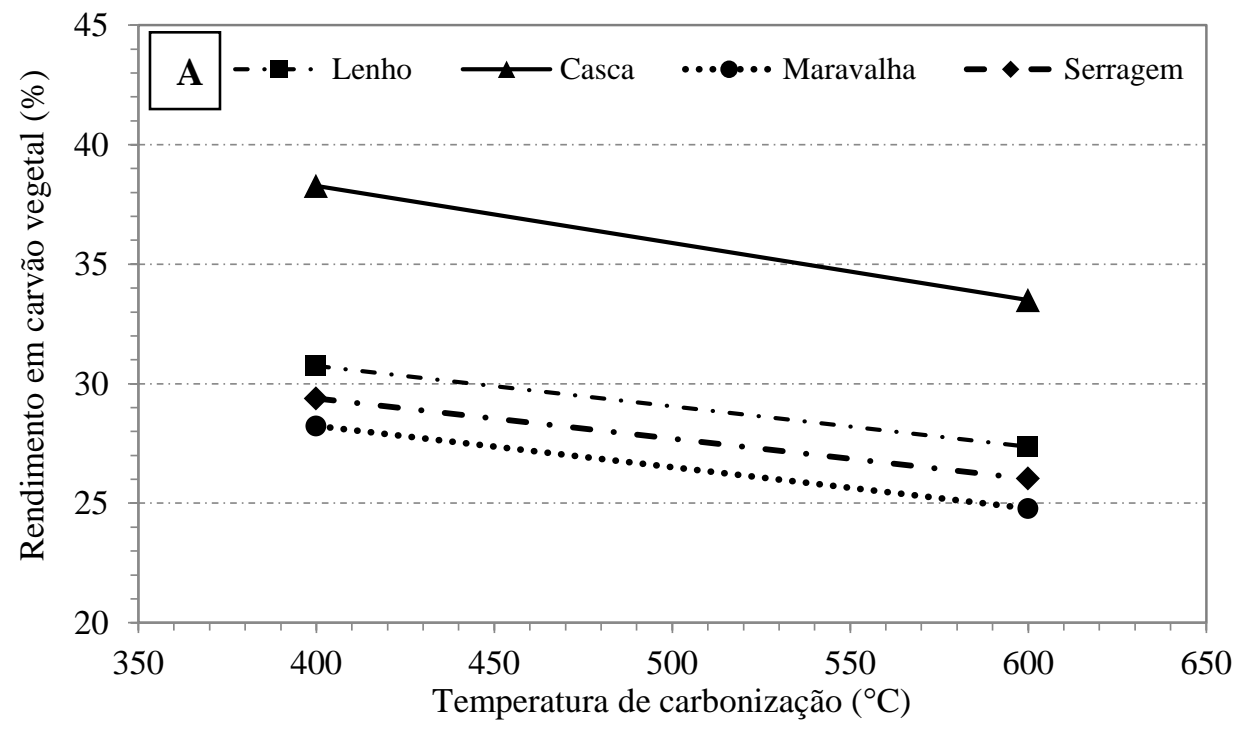



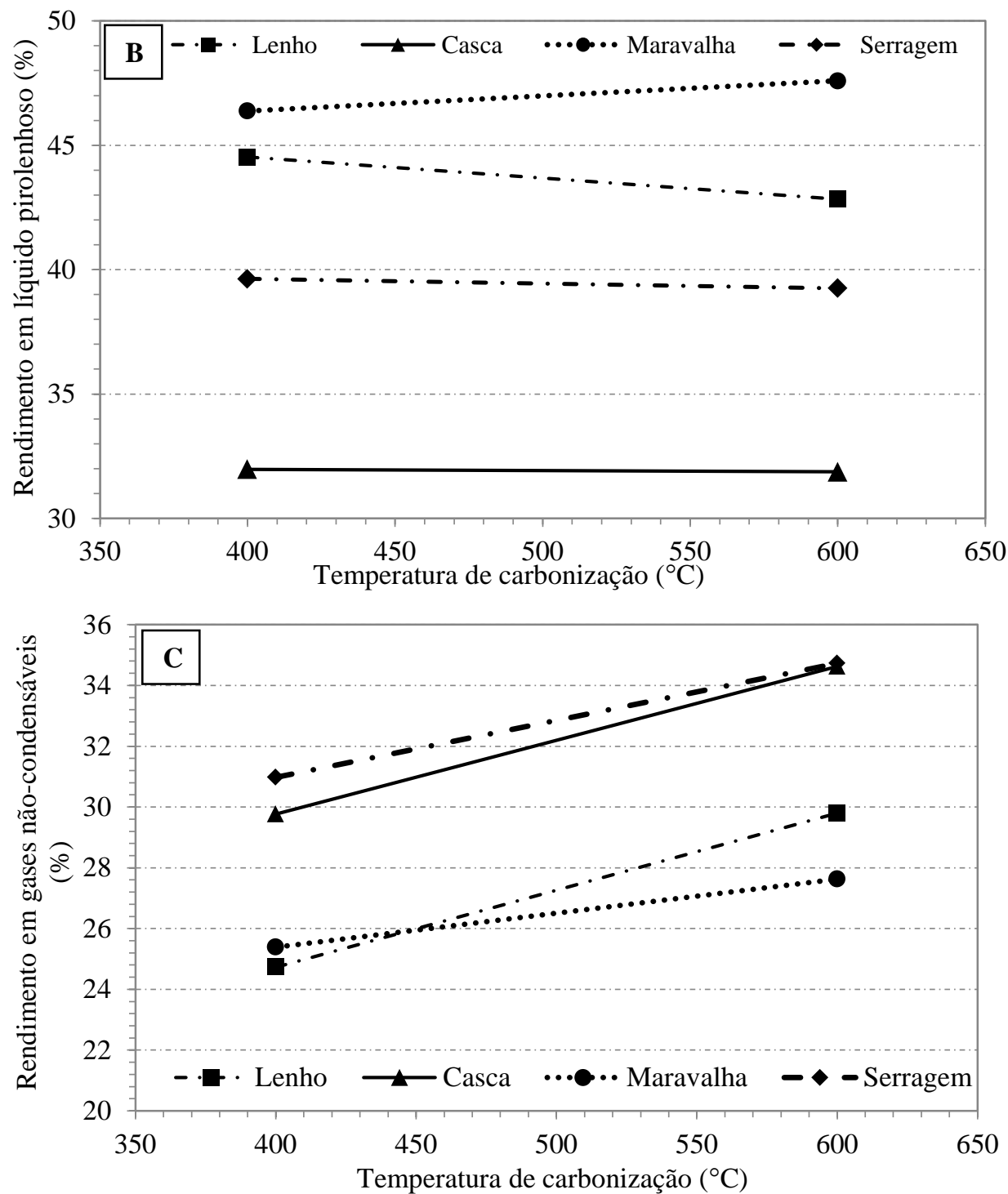

Figura 1: Influência da temperatura de carbonização sobre o rendimento em carvão vegetal (A), em líquido pirolenhoso (B) e em gases não-condensáveis (C).

Figure 1: Influence of the carbonization temperature on charcoal yield (A), pyroligneous liquid (B) and non-condensable gases $(\mathrm{C})$.

Observa-se, na Tabela 2, uma resposta negativa do teor de materiais voláteis ao se elevar a temperatura máxima de carbonização.

Tabela 2: Teores de matérias voláteis (TMV), de cinzas (TCZ), de carbono fixo (TCF) e rendimento em carbono fixo (RCF) dos carvões analisados.

Table 2: Volatile matter (VM), ash (A), fixed carbon (FC) and fixed carbon yield (FCY) of the analyzed charcoal.

\begin{tabular}{ccc|ccccc|cc}
\hline \multirow{2}{*}{ Material } & \multicolumn{2}{c}{ TMV $(\boldsymbol{\%})$} & \multicolumn{2}{c}{ TCZ $(\boldsymbol{\%})$} & \multicolumn{2}{c}{ TCF $(\boldsymbol{\%})$} & \multicolumn{2}{c}{ RCF $(\boldsymbol{\%})$} \\
\cline { 2 - 8 } & $\mathbf{4 0 0}^{\circ} \mathbf{C}$ & $\mathbf{6 0 0}^{\circ} \mathbf{C}$ & $\mathbf{4 0 0}^{\circ} \mathbf{C}$ & $\mathbf{6 0 0}^{\circ} \mathbf{C}$ & $\mathbf{4 0 0}^{\circ} \mathbf{C}$ & $\mathbf{6 0 0}^{\circ} \mathbf{C}$ & $\mathbf{4 0 0}^{\circ} \mathbf{C}$ & $\mathbf{6 0 0}^{\circ} \mathbf{C}$ \\
\hline Lenho & $19,25^{\mathrm{bA}}$ & $7,50^{\mathrm{bB}}$ & $1,50^{\mathrm{bA}}$ & $1,75^{\mathrm{bA}}$ & $79,25^{\mathrm{aB}}$ & $90,75^{\mathrm{aA}}$ & $24,35^{\mathrm{bA}}$ & $24,84^{\mathrm{bA}}$ \\
Casca & $24,01^{\mathrm{aA}}$ & $10,50^{\mathrm{aB}}$ & $4,25^{\mathrm{aA}}$ & $4,51^{\mathrm{aA}}$ & $71,75^{\mathrm{bB}}$ & $85,02^{\mathrm{bA}}$ & $27,45^{\mathrm{aA}}$ & $28,47^{\mathrm{aA}}$ \\
Maravalha & $22,12^{\mathrm{aA}}$ & $6,75^{\mathrm{bB}}$ & $1,01^{\mathrm{bA}}$ & $1,26^{\mathrm{bA}}$ & $77,07^{\mathrm{aB}}$ & $92,03^{\mathrm{aA}}$ & $21,73^{\mathrm{cA}}$ & $22,80^{\mathrm{cA}}$ \\
Serragem & $20,75^{\mathrm{bA}}$ & $7,52^{\mathrm{bB}}$ & $0,75^{\mathrm{cA}}$ & $1,25^{\mathrm{bA}}$ & $78,51^{\mathrm{aB}}$ & $91,25^{\mathrm{aA}}$ & $23,06^{\mathrm{bcA}}$ & $23,75^{\mathrm{bcA}}$ \\
\hline
\end{tabular}

Letras minúsculas diferentes na mesma coluna indicam diferenças estatísticas entre as variáveis para cada tipo de resíduo do processamento da madeira de Eucalyptus pellita; letras maiúsculas diferentes na mesma linha indicam diferenças estatísticas entre as temperaturas de carbonização. Comparação múltipla pelo teste de Tukey a 95\% de probabilidade. 

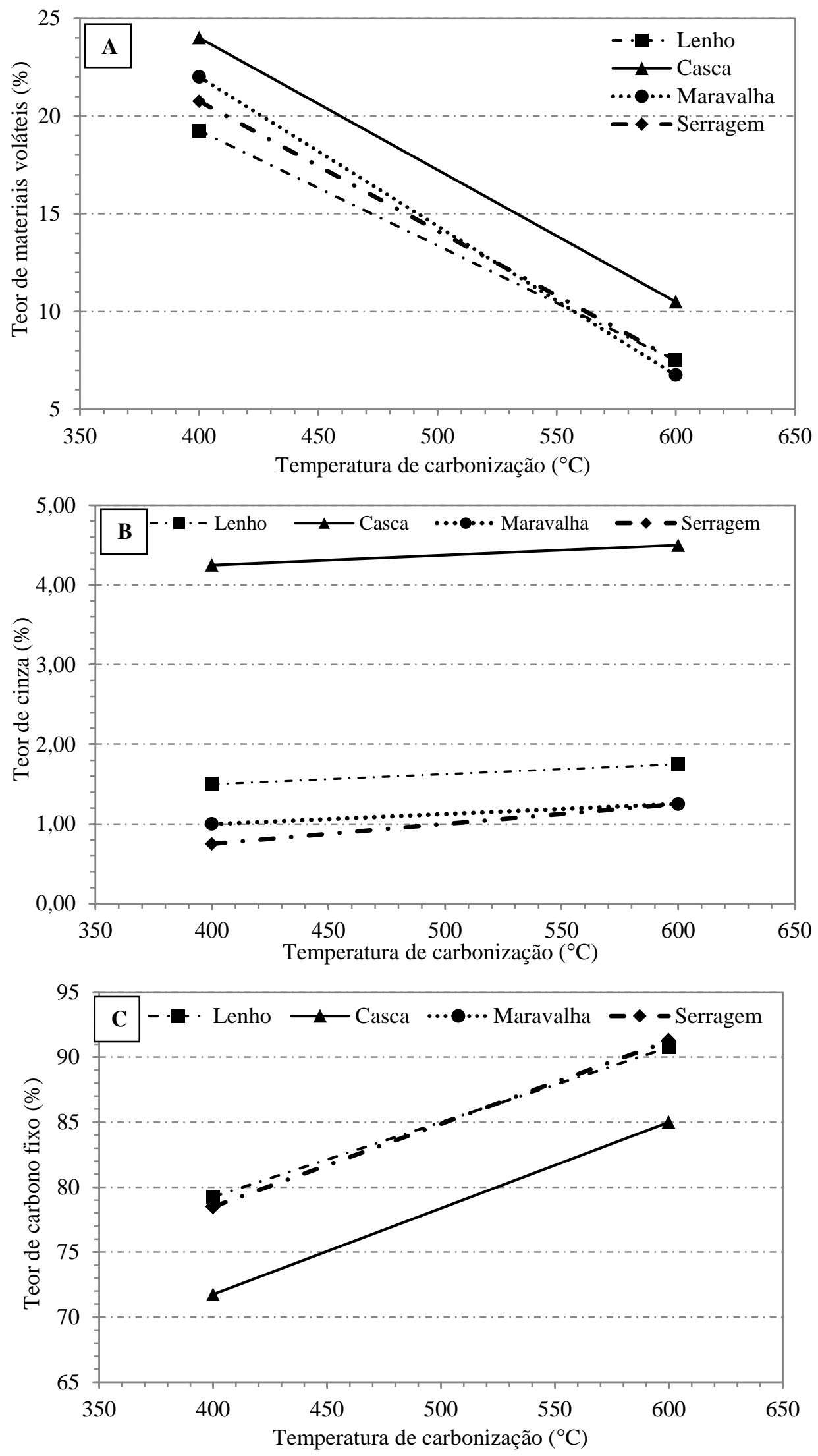


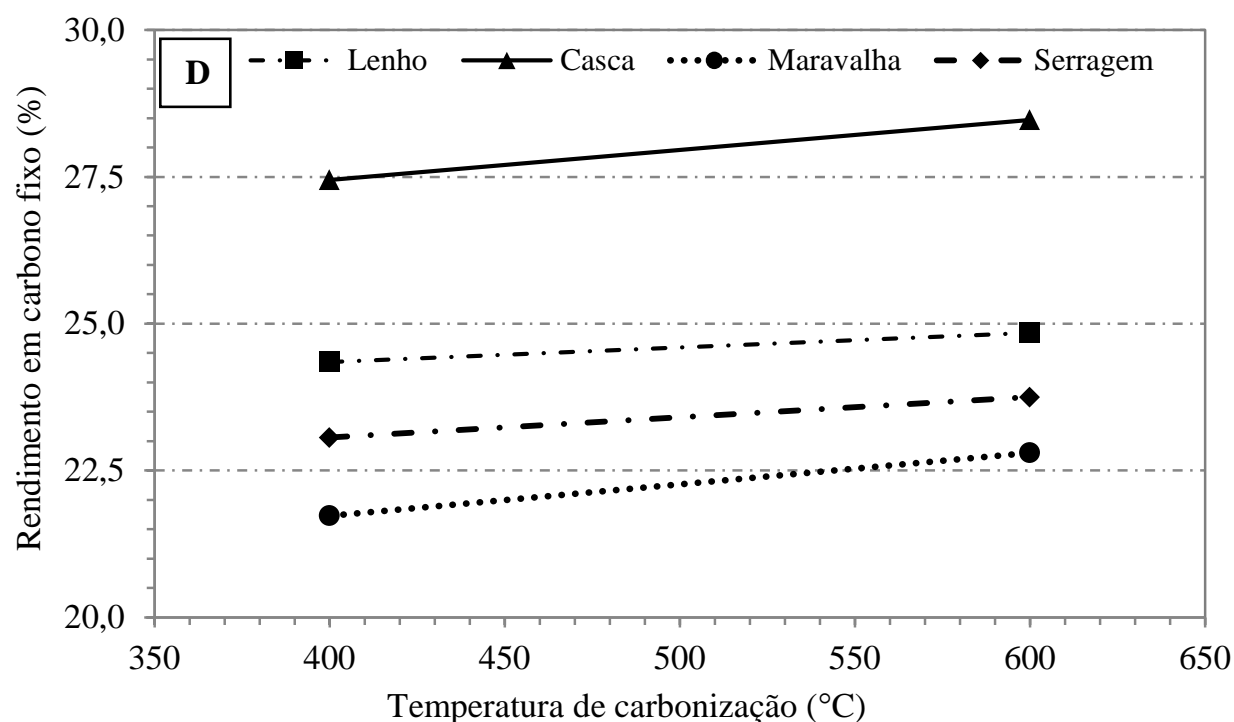

Figura 2: Influência da temperatura de carbonização sobre o teor de materiais voláteis (A), teor de cinza (B), teor de carbono fixo (C) e rendimento em carbono fixo (D).

Figure 2: Influence of the carbonization temperature on the content of volatile materials (A), ash content (B), fixed carbon content (C) and yield on fixed carbon (D).

Quanto a umidade de equilíbrio dos carvões e dos briquetes produzidos, observa-se na Tabela 3, que não houve diferença significativa quando se analisa uma mesma temperatura de carbonização. Porém, nota-se um sensível aumento quando os materiais foram carbonizados à $600{ }^{\circ} \mathrm{C}$ (Figura $3 \mathrm{~A}$ ).

Tabela 3: Umidade de equilíbrio (UE), massa específica aparente (MEA), degradação forçada (DF) e degradação natural (DN) dos carvões e dos briquetes produzidos.

Table 3: Equilibrium moisture content (EM), apparent density (AD) forced degradation (FD) and natural degradation (ND) of charcoal and briquettes produced.

\begin{tabular}{|c|c|c|c|c|c|c|c|c|}
\hline \multirow{2}{*}{ Material } & \multicolumn{2}{|c|}{ UE (\%) } & \multicolumn{2}{|c|}{$\operatorname{MEA}\left(\mathrm{g} \mathrm{cm}^{-3}\right)$} & \multicolumn{2}{|c|}{ DF $\left(\right.$ g min $\left.^{-1}\right)$} & \multicolumn{2}{|c|}{ DN $\left(g \min ^{-1}\right)$} \\
\hline & $400{ }^{\circ} \mathrm{C}$ & $600{ }^{\circ} \mathrm{C}$ & $400{ }^{\circ} \mathrm{C}$ & $600{ }^{\circ} \mathrm{C}$ & $400{ }^{\circ} \mathrm{C}$ & $600{ }^{\circ} \mathrm{C}$ & $400{ }^{\circ} \mathrm{C}$ & $600{ }^{\circ} \mathrm{C}$ \\
\hline Carvão do lenho & $8,49^{\mathrm{nsB}}$ & $11,27^{\mathrm{nsA}}$ & $0,25^{\mathrm{bA}}$ & $0,21^{\mathrm{bA}}$ & $0,90^{\mathrm{aA}}$ & $0,58^{\mathrm{aB}}$ & $0,21^{\mathrm{nsA}}$ & $0,11^{\mathrm{bB}}$ \\
\hline Briquete da casca carbonizada & $8,43^{\mathrm{nsB}}$ & $11,54^{\mathrm{nsA}}$ & $0,51^{\mathrm{aA}}$ & $0,51^{\mathrm{aA}}$ & $0,74^{\mathrm{abA}}$ & $0,37^{\mathrm{bB}}$ & $0,25^{\mathrm{nsA}}$ & $0,23^{\mathrm{aA}}$ \\
\hline Briquete da maravalha carbonizada & $8,53^{\mathrm{nsB}}$ & $11,60^{\mathrm{nsA}}$ & $0,49^{\mathrm{aA}}$ & $0,53^{\mathrm{aA}}$ & $0,39^{\mathrm{bA}}$ & $0,34^{\mathrm{bA}}$ & $0,21^{\mathrm{nsA}}$ & $0,05^{\mathrm{cB}}$ \\
\hline Briquete da serragem carbonizada & $8,17^{\mathrm{nsB}}$ & $11,01^{\mathrm{nsA}}$ & $0,48^{\mathrm{aA}}$ & $0,52^{\mathrm{aA}}$ & $0,42^{\mathrm{bA}}$ & $0,31^{\mathrm{bB}}$ & $0,23^{\text {nsA }}$ & $0,09^{\mathrm{cB}}$ \\
\hline
\end{tabular}

Letras minúsculas diferentes na mesma coluna indicam diferenças estatísticas entre as variáveis para cada tipo de resíduo do processamento da madeira de Eucalyptus pellita; letras maiúsculas diferentes na mesma linha indicam diferenças estatísticas entre as temperaturas de carbonização. Comparação múltipla pelo teste de Tukey a 95\% de probabilidade. 

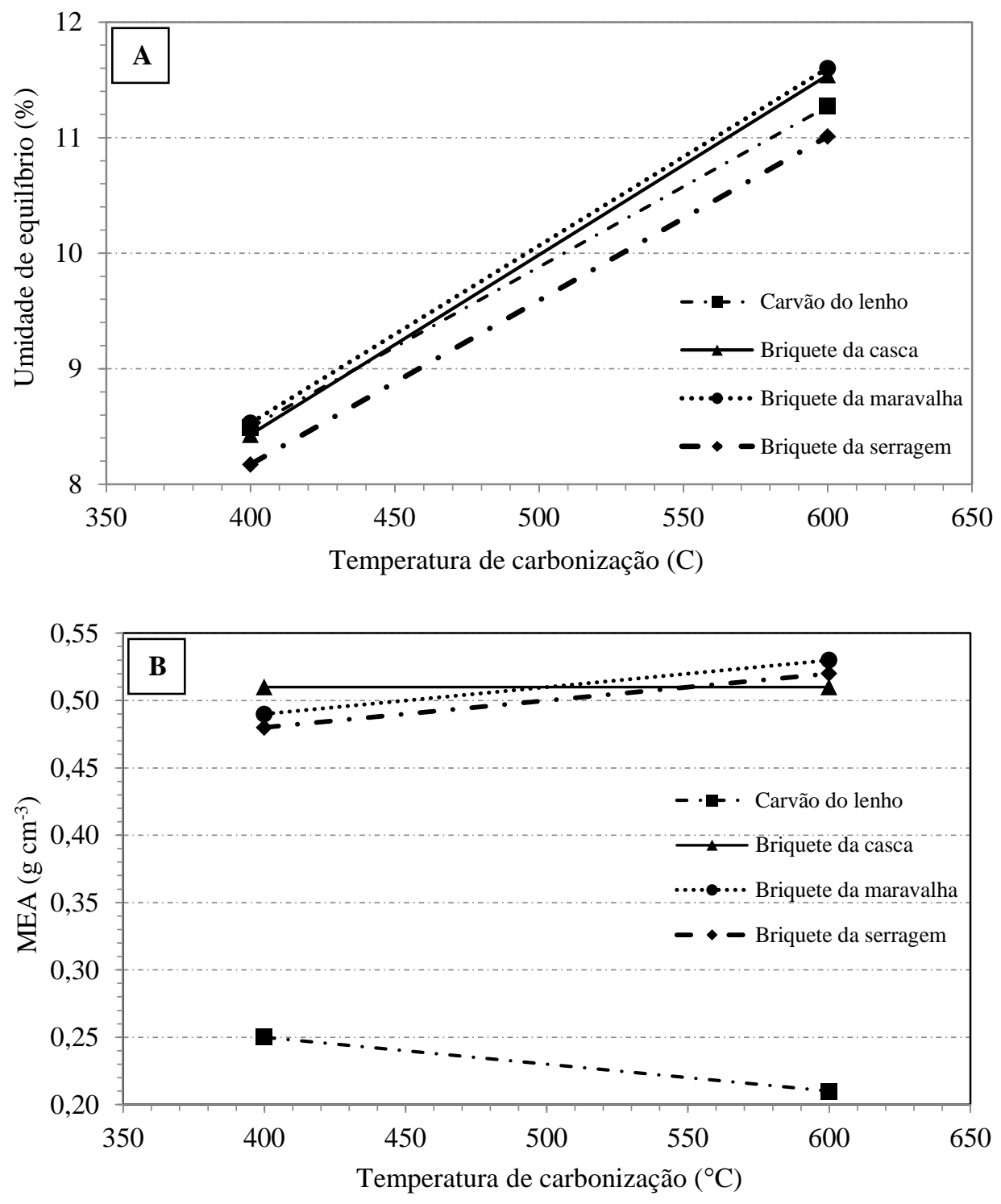

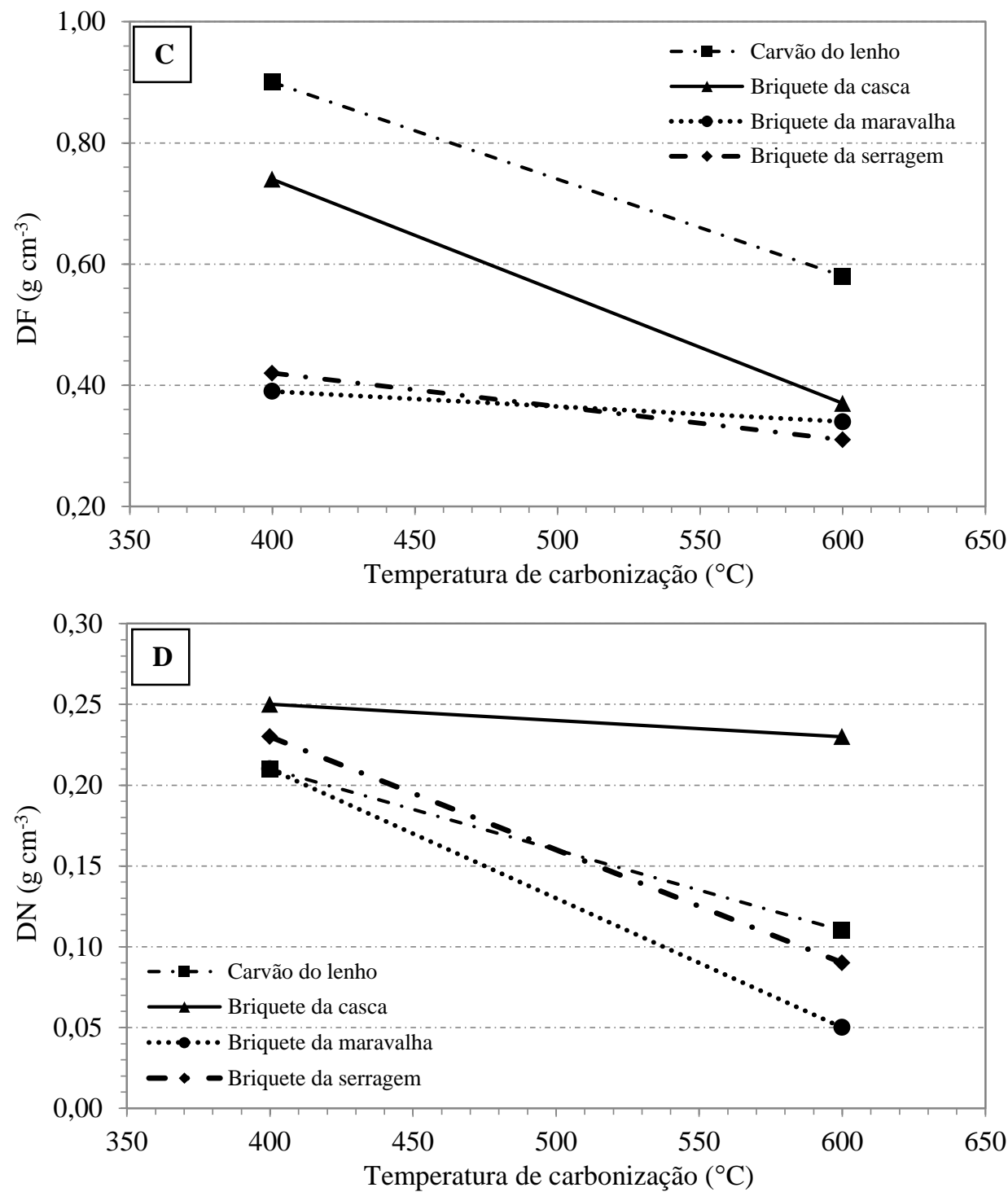

Figura 3: Influência da temperatura de carbonização sobre a umidade de equilíbrio (A), massa especifica aparente (B), degradação forçada (C) e degradação natural (D) dos briquetes produzidos com os resíduos analisados.

Figure 3: Influence of carbonization temperature on equilibrium moisture (A), apparent specific mass (B), forced degradation $(\mathrm{C})$ and natural degradation $(\mathrm{D})$ of the briquettes produced with the analyzed residues.

\section{DISCUSSÃO}

A carbonização da casca da madeira de Eucalyptus pellita apresentou o maior rendimento em carvão vegetal $(38,27 \%)$, quando a temperatura máxima foi de $400{ }^{\circ} \mathrm{C}$, sendo este valor $54,44 \%$ superior ao menor rendimento observado para a carbonização da maravalha sob temperatura máxima de $600{ }^{\circ} \mathrm{C}(24,78 \%)$. Pode-se ainda observar, na Figura 1A, o efeito da temperatura de carbonização sobre o rendimento gravimétrico em carvão da casca, significativamente maior, quando comparado aos rendimentos da maravalha e da serragem. Esse efeito também foi observado por Vital et al. [13], estudando a influência da inclusão da casca no rendimento e na qualidade do carvão vegetal de Eucalyptus grandis.

Para o rendimento em líquido pirolenhoso foi observado uma tendência bem definida (Figura 1B). Os valores variaram entre $31,87 \%$ (carvão da casca/600 ${ }^{\circ} \mathrm{C}$ ) e $47,59 \%$ (carvão de maravalha/600 ${ }^{\circ} \mathrm{C}$ ), sendo essa variação de 49,32\%. O aumento da temperatura de carbonização eleva a quantidade de gases formados (condensáveis e não-condensáveis) sendo que, dentre os condensáveis, os vapores colaboraram para aumentar a quantidade de líquido pirolenhoso obtido [24].

No que se refere ao rendimento em gases não-condensáveis, para os resíduos analisados, observouse um ligeiro aumento diante do aumento da temperatura máxima de carbonização (Figura 1C). Os valores 
situam-se num intervalo de $24,73 \%$ (carvão do lenho/400 ${ }^{\circ} \mathrm{C}$ ) a $34,73 \%$ (carvão de serragem/600 ${ }^{\circ} \mathrm{C}$ ). Os maiores valores (Tabela 1) foram observados para a casca e serragem carbonizadas a $600{ }^{\circ} \mathrm{C}$. Temperaturas elevadas degradam mais o material possibilitando maiores liberações de gases [4,25].

Os teores de matérias voláteis apresentaram valores entre $6,75 \%$ (carvão de maravalha $/ 600^{\circ} \mathrm{C}$ ) e $24,00 \%$ (carvão da casca $/ 400^{\circ} \mathrm{C}$ ) em resposta às duas temperaturas de carbonização aplicadas. Contudo, apesar do carvão da casca ter apresentado o maior valor médio absoluto, não houve diferenças significativas (Tabela 2) entre os carvões de maravalha e de serragem (ambos carbonizados a $400{ }^{\circ} \mathrm{C}$ ). Da mesma forma, não foram detectadas diferenças entre os teores de matérias voláteis dos carvões de maravalha, serragem e do lenho, carbonizados a $600{ }^{\circ} \mathrm{C}$. O que se pode notar de forma bem evidente é que, para um mesmo material, a temperatura de carbonização exerceu efeito de diminuição dos teores de materiais voláteis (Figura 2A).

Os teores de cinzas variaram de $0,75 \%$ a $4,51 \%$, para os carvões da serragem, carbonizada a $400{ }^{\circ} \mathrm{C}$ e da casca carbonizada a $600{ }^{\circ} \mathrm{C}$, respectivamente. Neste caso, o maior valor apresentou-se $500 \%$ superior em relação ao menor valor (Tabela 2). É relevante mencionar que essa característica é bastante variável, podendo ser atribuída a diversos fatores tecnológicos e silviculturais [26]. Percebe-se que existe uma relação positiva significativa entre o teor de carbono fixo e a temperatura de carbonização. Para todos os tipos de resíduos do processamento da madeira carbonizados houve um aumento significativo no teor de carbono do carvão, em resposta ao aumento na temperatura (Figura 2C). Tais teores apresentaram valores compreendidos entre $71,75 \%$ (carvão de casca $/ 400{ }^{\circ} \mathrm{C}$ ) e $92 \%$ (carvão de maravalha/ $600{ }^{\circ} \mathrm{C}$ ) sendo o maior valor $28,22 \%$ superior ao menor. $\mathrm{O}$ aumento do teor de carbono fixo provocado pela elevação da temperatura final de carbonização é mencionado por diversos autores [3,4,27].

Os rendimentos em carbono fixo, produto dos respectivos rendimentos gravimétricos em carvão vegetal e dos teores de carbono fixo, apresentaram valores médios distribuídos num intervalo de $21,73 \%$ a $28,47 \%$ (Tabela 2), nos carvões de maravalha carbonizada a $400{ }^{\circ} \mathrm{C}$ e da casca carbonizada a $600{ }^{\circ} \mathrm{C}$, respectivamente. Segundo Andrade [12] o rendimento em carbono fixo é o parâmetro que melhor expressa a qualidade energética da matéria-prima lignocelulósica para a produção de carvão vegetal. Em função disso, sobressaiu-se o carvão da casca, carbonizada sob as duas temperaturas (400 e $600{ }^{\circ} \mathrm{C}$ ). Gomes e Oliveira [28] ressaltam que existe uma relação inversamente proporcional entre o rendimento em carvão vegetal e teor de carbono fixo. É possível que tal observação esteja vinculada às maiores higroscopicidades dos carvões produzidos a $600{ }^{\circ} \mathrm{C}$, pois ela relaciona-se com outras propriedades do carvão, como a porosidade e adsortividade [27, 29]. Além disso, a capacidade higroscópica do carvão vegetal aumenta em função do aumento da temperatura de carbonização, conforme concluído por Dias Júnior et al. [27] e observado neste trabalho (Figura 3A).

Não foram observadas diferenças significativas entre as massas específicas aparentes dos briquetes. Porém, elas se diferiram da massa específica dos carvões do lenho que apresentaram menor valor. Isto ocorreu porque, no caso dos briquetes, a compactação é efetuada, normalmente, objetivando incrementar maior unidade de massa por unidade de volume. Embora a variação da umidade de equilíbrio dos briquetes tenha provocado ligeiras variações nas massas específicas aparentes dos mesmos, não foram observados valores estatisticamente diferentes entre si. No entanto, com sensíveis aumentos em função da temperatura de carbonização (Figura 3B). Segundo os critérios de AFNOR [30], Dias Júnior et al. [23] e São Paulo [31] e os resultados da massa específica observados, os combustíveis obtidos são considerados satisfatórios para a utilização como combustível no preparo de alimentos, por meio da cocção. Assim, o uso em padarias e pizzarias, aquecimento de lareiras, queima direta em fornalhas de secadores de grãos, são alguns dos recomendados.

Em função do maior teor de matérias voláteis observados nos materiais carbonizados à $400^{\circ} \mathrm{C}(\mathrm{Ta}-$ bela 2), os ritmos de degradação térmica (forçada e natural) dos carvões do lenho e dos briquetes derivados deles, foram significativamente superiores. Durante a degradação natural, os briquetes que foram consumidos mais lentamente (Figura 3C e 3D) foram àqueles produzidos com os carvões com os menores teores de matérias voláteis, ou seja, da maravalha e da serragem carbonizadas em temperaturas máximas de $600{ }^{\circ} \mathrm{C}$ (Tabela 3). Do ponto de vista prático, a degradação térmica revela que os combustíveis com maiores densidades levarão mais tempo para se degradarem, até a completa calcinação, do que àqueles que apresentarem menores densidades (degradação mais rápida). De uma maneira bastante simples pode-se afirmar que, para apresentar uma alta eficiência energética, o briquete, além de demonstrar um elevado poder calorífico, deverá manter o fornecimento desta energia térmica durante o maior período de tempo possível [4, 23]. 


\section{CONCLUSÕES}

A carbonização do lenho, da casca, maravalha e da serragem sob temperatura de $600{ }^{\circ} \mathrm{C}$ resultou na produção de carvão vegetal com elevado teor de carbono fixo. Apesar disso, os briquetes produzidos a partir do carvão vegetal da casca de Eucalyptus pellita a $600{ }^{\circ} \mathrm{C}$ tiveram o maior ritmo de degradação térmica natural, sendo dessa forma pouco eficientes termicamente.

Houve relação positiva entre a temperatura de carbonização e a umidade de equilíbrio dos briquetes, produzidos com os resíduos carbonizados, sendo as maiores médias de umidade detectadas para os materiais carbonizados a $600{ }^{\circ} \mathrm{C}$.

A fim de se obter briquetes com elevado estoque de energia, representado por um alto teor de carbono fixo e que possa fornecer energia durante maior período de tempo (menor degradação térmica natural) sugere-se estudos que analisem briquetes produzidos em diferentes composições dos resíduos carbonizados a $600{ }^{\circ} \mathrm{C}$.

\section{BIBLIOGRAFIA}

[1] SANTIAGO, A. R., ANDRADE, A. M., "Carbonização de resíduos do processamento mecânico da madeira de eucalipto”, Ciência Florestal, v. 15, n.1, pp.1-7, 2005.

[2] WENZL, H. F. J., The chemical technology of wood. New York, Academic Press, 1970.

[3] DEMIRBAS, A., "Relationships between carbonization temperature and pyrolysis products from biomass", Energy Exploration \& Exploitation, v. 22, n. 6, pp. 411-420, 2004.

[4] SCATOLINO, M. V., NETO, L. F. C., PROTÁSIO, T. P., et al., "Options for generation of sustainable energy: production of pellets based on combinations between lignocellulosic biomasses", Waste and Biomass Valorization, v. 9, pp.479-489, 2018.

[5] BRITO, J. O., "Princípios de produção e utilização de carvão vegetal de madeira", IPEF (Documentos Florestais), v. 9, pp; 1-19, 1990.

[6] ANDRADE, A. M. de, CARVALHO, L. M. de, "Potencialidades energéticas de oito espécies florestais do Estado do Rio de Janeiro", Floresta \& Ambiente, v. 5, n. 1, pp. 24-42, 1998.

[7] GUILLÉN, M. D., MANZANOS, M. J., "Study of the volatile composition of an aqueous oak smoke preparation", Food Chemistry, v. 79, pp. 283-292, 2002.

[8] OLIVEIRA, J. B., GOMES, P. A., ALMEIDA, M. R., Carvão vegetal - destilação, carvoejamento, propriedades e controle de qualidade, Belo Horizonte, CETEC - Centro Tecnológico de Minas Gerais, 1982.

[9] OLIVEIRA, A. C., CARNEIRO, A. de C. O., et al., "Parâmetros de qualidade da madeira e do carvão vegetal de Eucalyptus pellita F. Muell”, Scientia Forestalis, v. 38, n. 87, pp. 431-439, 2010.

[10] ROSA R. A., ARANTES, M. D. C., PAES, J. B., et al., "Qualidade do carvão vegetal para uso doméstico", Journal of Biotecnology and Biodiversity, v. 3, n. 2, pp. 41-48, 2012.

[11] DIAS JÚNIOR, A. F., ANDRADE, A. M. de, WERNECK, V. S., et al., "Potencial energético de sete materiais genéticos de Eucalyptus cultivados no Estado do Rio de Janeiro", Scientia Forestalis, n. 108, pp. 478-485, 2015.

[12] ANDRADE, A. M., "Influência da casca de Eucalyptus grandis W. Hill ex Maiden no rendimento e qualidade de carvão vegetal", Dissertação de M.Ss1989. 86 f. PPGCF/UF, Viçosa, MG, Brasil, 1989.

[13] VITAL, B. R., ANDRADE, A. M., VALENTE, O. F., CAMPOS, J. C. C. "Influência da casca no rendimento e na qualidade do carvão vegetal de Eucalyptus grandis", IPEF, n. 41, pp. 44-49, 1989.

[14] KALIYAN, N., R. MOREY, V., "Natural binders and solid bridge type binding mechanisms in briquettes and pellets made from corn stover and switchgrass", Bioresource Technology, v. 101, n. 3, pp. 10821090, 2010.

[15] PAUlA, L. E. R., TRUGILHO, P. F., REZENDE, R. N., et al., "Produção e avaliação de briquetes de resíduos lignocelulósicos". Pesquisa Florestal Brasileira, v. 31, n. 61, pp. 103-112, 2011.

[16] PROTÁSIO, T. P., BUFALINO, L., MENDES, R. F., et al., "Torrefação e carbonização de briquetes de resíduos do processamento dos grãos de café”, Revista Brasileira de Engenharia Agrícola e Ambiental, v. 16, n. 11, pp. 1252-1258, 2012. 
[17] VIEIRA, A. T. O., NASCIMENTO, A. M., ANDRADE, A. M., et al., "Propriedades termoquímicas de briquetes produzidos com finos de carvão vegetal e resíduos de Pinus spp", Scientia Forestalis, v. 46, n.119, pp.483-493, 2018.

[18] NOGUEIRA, L. A. H., LORA, E. E. S., TROSSERO, M. A., et al., Dendroenergia: fundamentos e aplicações. Brasília, Interciência, 2000.

[19] DIAS JÚNIOR, A. F., ANDRADE, A. M. de, CARVAlHO, A. M., et al., "Produção de briquetes de moinha de carvão vegetal e resíduos lignocelulósicos visando uso bioenergético", Scientia Forestalis, v. 44, n. 110, pp. 453-462, 2016.

[20] MARTINS, M. P., BENICIO, E. L., DIAS JÚNIOR, A. F., et al., "Produção e avaliação de briquetes de finos de carvão vegetal compactados com resíduo celulósico proveniente da indústria de papel e celulose". Revista Árvore, v. 40, n. 1, pp. 173-180, 2016.

[21] AMERICAN SOCIETY FOR TESTING AND MATERIALS (ASTM), ASTM D 1762-64: Standard method for chemical analyses of wood charcoal, Phyladelphia, 1977.

[22] ASSOCIAÇÃO BRASILEIRA DE NORMAS TÉCNICAS (ABNT), NBR 11941: Madeira - Determinação da densidade básica, Rio de Janeiro, 2003.

[23] DIAS JÚNIOR, A. F., ANDRADE, A. M., COSTA JÚNIOR, D. S., "Caracterização de briquetes produzidos com resíduos agroflorestais”, Pesquisa Florestal Brasileira, v. 34, n. 79, pp. 225-234, 2014.

[24] KELYOUNSSI, K., HALIM, M., "An investigation on the texture and microstructure of carbonized charcoals produced by two-step pyrolysis”, Journal of Analytical and Applied Pyrolysis, n. 109, pp. 258-265, 2014.

[25] DIAS JÚNIOR, A. F., ANDRADE, C. R, PROTÁSIO, T. P., et al., "Pyrolysis and wood by-products of species from the Brazilian semi-arid region”, Scientia Forestalis, v. 46, n. 117, pp.65-75, 2018.

[26] TRUGILHO, P. F., SILVA, J. R. M., MORI, F. A., et al., "Rendimentos e características do carvão vegetal em função da posição radial de amostragem em clones de Eucalyptus", Cerne, v. 11, n. 2, pp. 178-186, 2005 .

[27] DIAS JÚNIOR, A. F., PIROLA, L. P., TAKESHYTA, S., et al., "Higroscopicity of charcoal produced in different temperatures", Cerne, v. 22, n. 4, pp. 423-430, 2016.

[28] GOMES, P. A., OLIVEIRA, J. B. Teoria da carbonização da madeira. Uso da madeira para fins energéticos. Belo Horizonte, CETEC, 1980.

[29] ANDRADE, A. M., DELLA LUCIA, R. M., “Avaliação da higroscopicidade do carvão vegetal e seus efeitos na resistência ao esmagamento", Floresta \& Ambiente, n. 2, 1995, pp. 20-26, 1995.

[30] ASSOCIATION FRANÇAISE DE NORMALISATION (AFNOR), NF EM 1860-2: Appareils, combustibles solides et allume-barbecue pour la cuisson au barbecue, Saint Denis, 2005.

[31] SÃO PAULO (ESTADO DE SÃO PAULO), Secretaria de Agricultura e Abastecimento. Resolução $n^{o}$ 40 SAA, de 14 de dezembro de 2015, São Paulo, SP, 2015.

\section{ORCID}

Alessandro de Paulo Silva Azarias Machado de Andrade Ananias Francisco Dias Júnior https://orcid.org/0000-0002-9959-3752

https://orcid.org/0000-0002-7246-1696 http://orcid.org/0000-0001-9974-0567 